\title{
The Localization of UK Experience in Environmental Education in Fairy Lake Botanical Garden, Shenzhen, China
}

\author{
Shan Li, Qing Wang and Tao Wang \\ Center of Service \& Education, Fairy Lake Botanical Garden, Shenzhen \& Chinese Academy of Sciences, Shenzhen 518004, China
}

\begin{abstract}
In China, the environmental education (EE) is a brief new but popular topic in recent several years as a method to cope with the gap between nature and children. EE was started in UK with a long-term development and the useful experience can be utilized for the Chinese EE development. As a case study, the experiences of UK organizations were summarized and applied in the EE system in Fairy Lake Botanical Garden in Shenzhen (SZBG), China. The localization of UK's experience in the EE development in SZBG in terms of EE program, course content and resource was summarized in this paper. There are also discussions for the future update of EE in SZBG and for other local organizations like botanical gardens, wetland parks, nature reserve etc.
\end{abstract}

Key words: Environmental education, botanical garden, localization.

\section{Introduction}

In 2013, there are 53.2\% people living in cities of China and the number is estimated for $70 \%$ in the future, meaning that the next generation will grow up in a nature-limited environment [1]. This situation resulted in a gap between kids and nature, which was called by Richard Louv, "the nature-deficient disorder kids”. This is not a serious clinical disease, and the symptoms are manifested in more time spent on social media and other indoor activities instead of playing in nature [2], leading to an increasing probability of physical problems, such as teenage obesity and diseases [3, 4]. Besides, less knowledge about nature and experience in nature also weaken the deep link between the young generation and the nature.

Environmental education (EE) is mentioned as an integrated method about teaching the whole society how to live within the surrounding environment and how to use the resource from the environment $[5,6]$.

Corresponding author: Shan Li, M.Sc., research fields: co-evolution, environmental education, citizen science and volunteer.
EE helps teenagers and adults to increase time spent in nature and increase the physical healthy [7-9]. EE also helps to increase the cognition of the surround environment, personal social skills and change their environmental attitude and behavior [10-13]. In China, this is also a creative way to improve the scientific knowledge, social skill and environment conservation concern under the policy of “ecological development”.

The modern EE in UK can be traced back to 1970s where there were several worldwide known meetings like UN Conference on the Human Environment in Stockholm (1972), Belgrade Charter (1975) and Tiblisi Declaration (1977) defining what EE is, the methodology and the following development directions etc. [5]. Later, projects like the forest school, the eco-school and the field study centers (FSC) were implemented either by the government or non-government organizations [14]. There are upsurges and low tides of EE in UK. And after 30 years' development, more contents related to sustainability, biodiversity, climate change rather than only the traditional conservation knowledge are included in the EE courses [15, 16]. 
In this article, Fairy Lake Botanical Garden in Shenzhen (SZBG) was used as a case study to examine the information and experiences collected from UK. Information and experience about EE in UK came from the visits to botanical gardens, national parks, universities, conservation organizations, gardens and parks, study centers and social business companies. The paper was divided into three topics, namely EE types, the course content and resources.

\section{The Types of EE Activity}

There are three types of EE in UK, formal education, informal education and non-formal education, which normally were established depending on the organization diversity.

The EE program in SZBG was established in 2014. In the beginning, the courses were aimed at primary school students as an informal education activity at weekends. Currently, a system consists of courses is divided into formal education, informal education and non-formal activates. The age groups to attend EE go from primary school students to adults, and activities include school visiting, citizen science, volunteer training, exhibition, public culture activities etc.

\section{The Course Structure and Content of EE}

Apart from only considering conservations, the topics of EE now expand to sustainability, globalization, citizenship, biodiversity and climate change etc. An EE activity is structured in goals, process and feedbacks. Besides delivering knowledge, the goals of EE also include to increase the positive attitude towards conservation, pro-behavior intention and behavior change etc. [17]. Social skills and the young personal development, e.g., critical thinking are also considered as the learning goals for EE [18]. The goal of an EE activity is also depending on the audience group. By analyzing the group characteristics, the goals were set up more specifically.

The process of EE is more fixed in formal education but flexible in non-formal education. The school education occupied a key part of the formal EE programs. In the school sessions, the content is organized by a teaching planning describing the goals, process, knowledge and materials corresponding to the curriculum [19]. School teachers bring students to educational sites for a 45-minute course as part of the school study. Informal education can last from several hours to several days. Non-formal education is more public involved and full of entrainment activities by amazing cross-sides cooperation. Live music, art exhibition, art workshop, outdoor training and camping can be involved into this kind of EE.

The feedback parts in EE activities are important. However, the running programs appeared that there was limited time to do a survey in most of the EE courses. In formal EE courses, the school teachers were asked for a comprehensive feedback by emails after the course but the return rate is relatively low. Most participants in the informal EE course are asked to give brief oral feedback or several questions in emails. However, this kind of feedback reflects mostly the consequences of the process going and the knowledge gain. Some additional feedback methods are conducted by universities as research projects. This kind of feedback would be more reliable by testing the short- and long-term effect in a systematic way. Not only EE but also some social impacts were measured by the researchers depending on the requirements of the funding source.

In SZBG, previous education course only covered the outdoor course "the shady plant garden exploration" and the indoor course "leaves-the green factory". After the new set of EE system and the resource survey, the topic of EE course expanded to the scientific education like lab exploration and citizen science, environmental conservation, climate change, citizenship and cultural activities. A teaching outline showing the course goals, process and knowledge points, time schedule, and materials is prepared for EE staff to read before they start the EE course. Feedbacks in SZBG started from 2016 by the volunteer training projects. To examine the 
effect on plant knowledge increase of volunteer training participation was the first purpose for this feedback. Afterwards the feedback continued to test the attitude, awareness, pro-environmental behaviors of the volunteers.

\section{Resource: Site, Publication and Staff}

A successful on-going EE activity is related to the existing organization resources like the place and the staff. The staff number and types are the key point to implement EE activity. For instance, a large outdoor camping activity held in a botanical garden will not be started without experts in outdoor activities and safety.

In UK, the EE staffs are fully-paid or part-time teachers with special license are employed by the organizations. Education officers are responsible for the education course without a teaching license. Volunteers can play roles as the EE educators as well. For volunteers, apart from contributing their time and personal skills to the botanical garden to feel fulfilling, they can also learn plants and environmental knowledge, which helps to reach a more positive attitude towards the environment and biodiversity conservation and improves their behavior intentions and pro-environment behaviors [20]. Normally volunteers are non-academic participants. Therefore, volunteer training before the voluntary service is highly required. Some of the foregoing backgrounds from the volunteers could be considered during both recruitment and the training course section. For instance, education volunteer candidates who have ability in leading the activity, interpretation and education psychology will be considered a plus to be the volunteer role.

Publications like the training text books and activity booklets were written as essential supports to the EE course for both student courses and school teacher training. Some activity booklets were designed for the students to collect different signs and stamps to increase their interests and to deepen the effect on EE learning.

In SZBG, there are four education officers responsible for the school visiting by combining the school curriculum and the garden resource especially the labs and the gardens of specific living collections. In addition, the SZBG had a group of 130 volunteers from 2014, covering interpretation and conservation tasks, among which 35 volunteers are undertaking the EE course.

Three textbooks, moss, cycads and butterfly as the reference to the $\mathrm{EE}$ education training have been published. These topics cope with the current researches in the botanical garden, in which the authors can easily find the scientific reference and the scientists as training teachers for a more accurate and rigorous training.

\section{Discussion}

After combining the aforementioned work in SZBG and the UK experience, there are several points to be discussed for a better effect of the exotic EE experience localization.

First, communication is important in both internal and external cooperation. As EE is a new and cross-department task, both audience from internal like the team leaders, colleagues in other related departments and external like volunteer groups, local communities, local schools etc. needs to understand the reason to set up EE activates and give adequate supports to follow the new policy, method, organization structure and processes. Good communication also helps stakeholders in one project to achieve an agreeable situation.

Second, not only starting EE courses, there will be numerous goals in different levels for one organization. To weigh these goals and set priorities takes time but it will be useful to explore the most critical goals. The authors argue that priorities of goals should be considered firstly by the mission and vision of one organization. But in most cases, a strong team leader will change the priority at any time of the activities. So to balance the goals in different level will be a continuous issue. 
Third, not only clear task goals should be set up for EE activity but how to set an effective evaluation methodology is significant. The authors already thought highly of the feedback evaluation. However, the time limitation for feedback bothered the educators in both UK and SZBG. If any feedback tools can be used as part of the course instead of a separate step, the effect measurement and data collection will need to be user-friendly.

\section{Acknowledgments}

The authors are grateful to China Union of Botanical Garden (CUBG) for financial support of this work. Great appreciation also goes to our colleagues and the volunteer group of SZBG.

\section{References}

[1] World Bank and the Development Research Center of the State Council, P. R. China. 2014. Urban China: Toward Efficient, Inclusive and Sustainable. Washington DC.

[2] Rideout, V. J., Foehr, U. G., and Roberts, D. F. 2010. Generation M2 Media in the Lives of 8- to 18-Year-Olds. Kaiser Family Foundation.

[3] Ogden, C. L., Carroll, M. D., Curtin, L. R., Lamb, M. M., and Flegal, K. M. 2010. "Prevalence of High Body Mass Index in US Children and Adolescents, 2007-2008.” JAMA 303 (3): 242-9.

[4] Lachowycz, K., and Jones, A. P. 2011. "Greenspace and Obesity: A Systematic Review of the Evidence.” Obes. Rev. 12 (5): e183-9.

[5] UNESCO. 1978. Final Report: Intergovernmental Conference on Environmental Education, Organized by UNESCO in Cooperation with UNEP, Tbilisi, USSR, 14-26 October 1977. Paris: UNESCO ED/MD/49.

[6] William, S. B. 1969. "The Concept of Environmental Education.” Environmental Education 1 (1): 30-1.

[7] Dadvand, P., Villanueva, C. M., Font-Ribera, L., Martinez, D., Basagaña, X., Belmonte, J., Vrijheid, M., Grazuleviciene, R., Kogevinas, M., and Nieuwenhuijsen, M. J. 2014. "Risks and Benefits of Green Spaces for Children: A Cross-Sectional Study of Associations with Sedentary Behavior, Obesity, Asthma and Allergy.” Environmental Health Perspectives 122 (12): 1329-35.

[8] Dadvand, P., Nieuwenhuijsen, M., Esnaola, M., Forns, J., Basagaña, X., Alvarez-Pedrerol, M., Rivas, I., López-Vicente, M., De Castro Pascual, M., Su, J., Jerrett, M., Querol, X., and Sunyer, J. 2015. “Green Spaces and
Cognitive Development in Primary Schoolchildren.” Proceedings of the National Academy of Sciences 112 (26): 7937-42.

[9] Lovasi, G. S., Quinn, J. W., Neckerman, K. M., Perzanowski, M. S., and Rundle, A. 2008. "Children Living in Areas with More Street Trees Have Lower Prevalence of Asthma.” Journal of Epidemiol Community Health 62 (7): 647-9.

[10] Damerell, P., Howe, C., and Milnergulland, E. J. 2013. "Child-Orientated Environmental Education Influences Adult Knowledge and Household Behaviour." Environmental Research Letters 8 (1): 015-6.

[11] Ajaps, S., McLellan, R., and Gritter, K. 2015. “We Don’t Know Enough: Environmental Education and Pro-environmental Behaviour Perceptions.” Cogent Education 2 (1): 1124490.

[12] Shay-Margalit, B., and Rubin, O. D. 2016. "Effect of the Israeli ‘Green Schools’ Reform on Pupils’ Environmental Attitudes and Behavior.” Society \& Natural Resources 30 (1): $112-28$.

[13] Williams, D. R., and Dixon, S. P. 2013. "Impact of Garden-Based Learning on Academic Outcomes in Schools: Synthesis of Research between 1990 and 2010.” Review of Educational Research 83 (2): 211-35.

[14] O’Brien, L. 2009. "Learning Outdoors: The Forest School Approach.” Education 3-13 37 (1): 45-60.

[15] Sellmanna, D., and Bogner, F. X. 2013. "Climate Change Education: Quantitatively Assessing the Impact of a Botanical Garden as an Informal Learning Environment.” Environmental Education Research 19 (4): 415-29.

[16] Vare, P., and Scott, W. 2007. "Learning for a Change: Exploring the Relationship between Education and Sustainable Development." Journal of Education for Sustainable Development 1 (2): 191-8.

[17] Russ, A. 2014. Measuring Environmental Education Outcomes. Ithaca, NY and Washington, DC: EECapacity project, Cornell University.

[18] De Vreede, C., Warner, A., and Pitt, R. 2014. "Facilitating Youth to Take Sustainability Actions: The Potential of Peer Education.” Journal of Environmental Education 45 (1): 37-56.

[19] Morgan, S. C., Hamilton, S. L., Bentley, M. L., and Myried, S. 2009. "Environmental Education in Botanic Gardens: Exploring Brooklyn Botanic Garden's Project Green Reach.” The Journal of Environmental Education 40 (4): 35-52.

[20] Guiney, M. S., and Oberhauser, K. S. 2009. “Conservation Volunteers' Connection to Nature." Ecopsychology 1 (4): 187-97. 